\title{
165. Comparison of approximate assessments of the harmfulness of mining shocks using ground and building foundation vibrations
}

\author{
Krystyna Kuzniar ${ }^{1}$, Krystyna Stec $^{2}$, Tadeusz Tatara ${ }^{3}$ \\ ${ }^{1}$ Pedagogical University of Cracow, Institute of Technology, Cracow, Poland \\ ${ }^{2}$ Central Mining Institute, Department of Geology and Geophysics, Katowice, Poland \\ ${ }^{3}$ Cracow University of Technology, Institute of Structural Mechanics, Cracow, Poland \\ ${ }^{1}$ Corresponding author \\ E-mail: ${ }^{1}$ krystyna.kuzniar@up.krakow.pl, ${ }^{2} k s t e c @ g i g . e u,{ }^{3}$ ttatara@pk.edu.pl
}

Received 14 November 2018; received in revised form 9 December 2018; accepted 20 December 2018 DOI https://doi.org/10.21595/jme.2018.20416

Check for updates

Copyright $(C) 2018$ Krystyna Kuzniar, et al. This is an open access article distributed under the Creative Commons Attribution License, which permits unrestricted use, distribution, and reproduction in any medium, provided the original work is properly cited.

\begin{abstract}
Mining tremors belong to so-called paraseismic sources of vibrations and can be classified as the most intensive of such type sources of surface structures vibrations, hazardous for buildings. According to the soil-structure interaction effect, the ground vibrations are modified during their transmission to foundations of building. In consequence, the differences between the records of vibrations registered on the ground next to a building and at the building foundation (simultaneously), can be significant. The paper is focused on the analysis of the differences in the approximate assessments of the harmfulness of mine-induced rockbursts on the basis of simultaneously occurring free-field vibrations next to the building, or building foundation vibrations. The analysed vibrations were induced by shocks in the Upper Silesian Coalfield (USC), one of the most seismically active area in Poland. Typical administrative, masonry, low-rise actual building was taken into account. The harmfulness of mining-induced vibrations to the building was estimated using appropriately prepared scales for this region. Results corresponding to two versions of the scales were analysed: the new proposition - Mining Seismic Intensity Scale GSIS-2017, as well as its former version - the Mining Intensity Scale GSI-GZW $\mathrm{KW}_{\mathrm{W}}$ 2012. Both of the scales were considered in two versions: velocity version (basic), and acceleration version (auxiliary). It is worth mention that these scales base on the ground vibration parameters. However, for research and comparison purposes, they were applied also for building foundation vibrations.
\end{abstract}

Keywords: mine-induced vibrations, harmfulness of vibrations, GSI scale, GSIS scale, ground vibrations, building foundation vibrations.

\section{Introduction}

Mining tremors can induce ground motions. They appear in many countries on all continents (e.g. Australia, Canada, China, Czech Republic, France, Germany, India, Russia, South Africa [1-9]). Also, in Poland there are coal and copper mines. Exploitation of mineral resources in the mining areas of the Upper Silesian Coalfield (USC) (coal mines) and the Legnica-Glogow Copperfield (LGC) (copper ore) causes a number of negative phenomena on the surface. Continuous and unstable deformations are the cause of damages to building structures and their failures. In addition to terrain deformation, the cause of negative influence on residential buildings as well as underground facilities and impact on people staying in them are rockbursts. Their intensity often causes material damage in residential buildings as well as underground facilities. Mining shocks have so far not caused fatalities, which often occur in the case of earthquakes.

The mining exploitation of raw materials is carried out on the basis of mine plan of exploitation. An integral part of the plan is the assessment of static and dynamic resistance of buildings and underground infrastructure (water, gas and power lines). Determination of the harmfulness of vibrations covering large areas is not possible through detailed dynamic analysis of all surface and 
undreground structures. For this purpose, approximate methods based on empirical scales are used, as is done in seismic areas. The appropriate scales are prepared for practical, simple and easy evaluation of the rockburst harmfulness for surface structures [10-13]. One can estimate the level of vibration intensity on the basis of these scales. Intensity levels are correlated with effects of vibrations on buildings. It is worth mention that the scales are prepared and work using ground vibration parameters (ground vibration velocity or vibration acceleration, duration of intense vibration phase). In Poland, mining intensity scales for areas covered by mining have been developed in recent years [10-13].

This paper is an extension of the previous work [14] and it is focused on the analysis of the differences in the approximate assessments of the harmfulness of mine-induced rockbursts on the basis of simultaneously occurring ground vibrations next to the building, or building foundation vibrations. The analysis applies to the typical, actual, administrative, low-rise building located in the USC area. To do this, we use Mining Intensity Scales which base on the parameters of measured free-field or building foundation vibrations. In this region, essential differences in records of mine-related ground and building foundation vibrations (this applies both to acceleration and velocity) registered at the same time can be visible. In the paper the assessment of the surface vibration intensity according to the Mining Intensity Scales GSI-GZW $\mathrm{KW}_{\mathrm{K}}-2012$ $[11,13]$ and GSIS-2017 $[10,12]$ was carried out using simultaneously recorded ground vibrations and, for cognitive purposes, at building's foundation. The work analyses the impact of surface vibrations recorded in the considered area of the USC over several years. The impact of the place of vibration measurements on the level of vibration intensity was studied. Two versions of the scales have been used - the basis scale (based on velocities of vibrations) and supporting scale (based on accelerations of vibrations) [10-13].

\section{Full-scale measurements}

The estimation of the vibration harmfulness for the representative 2-storey masonry building with load-bearing walls (without basement) was done using full-scale measurements of ground and building foundation vibrations. Mining tremors were the source of vibrations. Horizontal components of vibrations were taken into account in this study. Vibrations of free-field and building foundations were recorded parallel to the transverse $(x)$ or longitudinal $(y)$ axis of the building. The sub-soil consists of a soil layer and layers of medium and fine sand and partially with yellow dust. A view of the considered office building and location of the accelerometers are presented in Fig. 1.

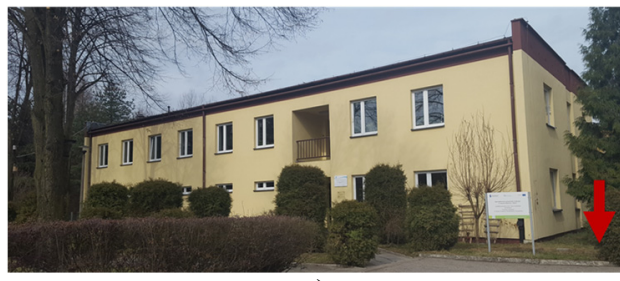

a)

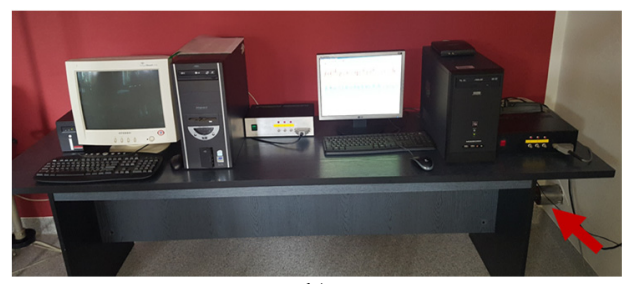

b)

Fig. 1. Location of sensors: a) ground; b) building at a ground level

Acceleration of vibrations were recorded using the so-called "an armed partition" accelerometers (see Fig. 1). Vibrations on the ground next to the analysed building and on the foundations were registered simultaneously. Full-scale tests were performed in a period of 8 years (long-term experimental monitoring) and nearly 500 pairs free-field - foundation accelerations in $x$ and $y$ directions were used in analysis. Vibrations caused by mining rockbursts with energy (En) from the range of $1.0 \cdot 10^{5}-4.0 \cdot 10^{9} \cdot \mathrm{J}$ and the vibrations with peak ground acceleration of horizontal components larger than $5 \mathrm{~cm} / \mathrm{s}^{2}$ were taken into account in the analysis. Full-scale measurements are described in detail in [14]. 


\section{Assessments of the mine-induced rockbursts harmfulness}

\subsection{Brief presentation of the mining intensity scales applied in the USC area}

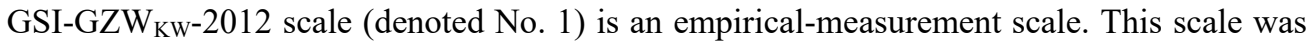
used in the USC region up to 2017 year for monitoring and assessing the influence of miningrelated ground vibrations both for structures and human percebility of vibrations $[11,13]$. The scale refers to buildings and very important underground structures (e.g. water, gas, sewage network) whose failure-free functioning provide the safety of residents. Scale No. 1 consists of two versions. The basic is a velocity version. Acceleration version of the scale is treated as auxiliary. The scale No. 1 associates values of the ground parameters with macro-seismic effects in structures. Impact assessment of surface mining-related vibrations is made using the maximum value of the resultant of ground velocity $P G V_{H}$ - (velocity version of the scale) and the maximum value of the resultant ground acceleration calculated using the filtered components of the horizontal vibration in the band to $10 \mathrm{~Hz}\left(P G A_{H 10}\right)$ in auxiliary version of the scale. The second parameter used in impact assessment is duration of the intensive phase of vibrations $t_{H v}$ and $t_{H a}$ for the velocity and acceleration, respectively $[11,13,14]$. Two versions of GSI-GZW $\mathrm{KW}_{\mathrm{W}}-2012$ scale (No. 1) are shown in Fig. 2.

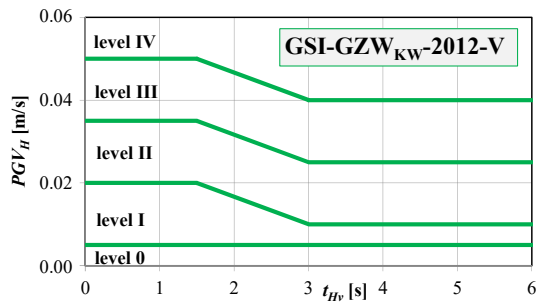

a)

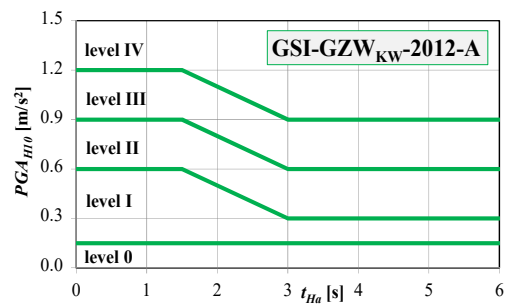

b)

Fig. 2. The GSI-GZWKW-2012 scale in: a) velocity, b) acceleration versions

Table 1. Results of mining rockbursts corresponding to levels of intensity in the scale No. 1 [14]

\begin{tabular}{|c|c|}
\hline $\begin{array}{c}\text { Level of vibration } \\
\text { intensity } I\end{array}$ & Specification of results according to the scale No. 1 \\
\hline 0 & Not noticeable; with no effect on buildings \\
\hline I & Being felt; only sporadically causing an increase in existing damage \\
\hline II & $\begin{array}{c}\text { Intensification of existing damage; enlargement of pre-existing damage to } \\
\text { non-structural elements }\end{array}$ \\
\hline III & $\begin{array}{c}\text { Non-structural damages; first damages of non-structural elements; extensive } \\
\text { enlargement of existing damages to non-structural elements }\end{array}$ \\
\hline IV & Structural damages; single damages of structural elements \\
\hline
\end{tabular}

Scale No. 1 allows to assess the influence of mining-related ground vibrations from not noticeable with no effect on buildings (level 0 of vibration intensity) up to the level IV in which structural damages in buildings may occur. The scale No. 1 introduces five levels of vibration intensity listed in Table 1. Given levels of vibration intensity are attributed to damage that may occur in structures. The scale No.1 refers to new buildings (in good technical condition) and old ones referring to building usually in poor condition.

The GSIS-2017 scale (denoted No. 2) is another version based on the previous GSI-GZW $\mathrm{KW}_{\mathrm{K}}-2012$ scale. The results of registration and observation of several strongest shocks occurring in the USC area in the years 2015-2016, with seismic energies exceeding $10^{8} \mathrm{~J}$ and the maximum values of vibration velocity $P G V>0.05 \mathrm{~m} / \mathrm{s}$, and acceleration with $P G A>1.0 \mathrm{~m} / \mathrm{s}^{2}$, were additionally included in the scale. In the scale, the technical condition and type of the building structure for its dynamic resistance were taken into account.

On the GSIS-2017 scale (No. 2), the impact of the shock is also expressed by measuring the 
level of seismic intensity. These levels are classified based on the recorded and/or predicted free-field vibration parameters. These parameters are correlated with macroseismic observations in buildings described by levels of vibration harmfulness. The parameters of the classification are the same as parameters used in the case of GSI-GZW $\mathrm{KW}_{-2} 2012$ scale (No. 1).

The GSIS-2017 scale distinguishes 7 levels of seismic intensity (from 0 to VI), which were assigned the effects of free-field vibrations on buildings and linear underground infrastructure and human percebility on vibrations and the inconvenience of using buildings, in correlation with parameters of free-field vibration (see Fig. 3). The GSIS-2017 scale gives the level of vibration intensity (IV-VI) at which structural damage to buildings may occur together with a description of damage to buildings and the level of harmfulness of vibrations - comp. Table 2. It should be emphasized that VI level has not been verified by measurement.

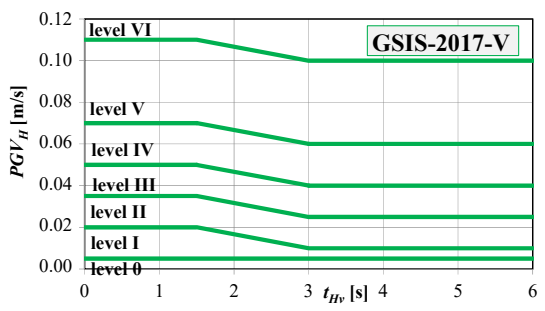

a)

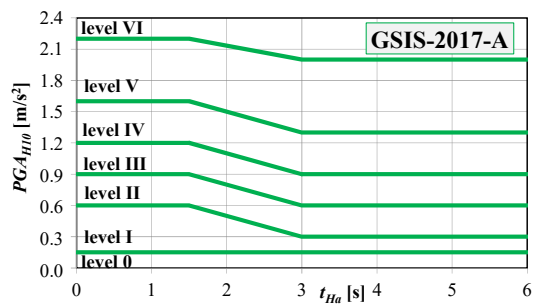

b)

Fig. 3. The GSIS-2017 scale in: a) velocity, b) acceleration versions

Table 2. Results of mining rockbursts corresponding to levels of intensity in the GSIS-2017 scale (No. 2)

\begin{tabular}{|c|c|}
\hline Level of vibration intensity $I_{\text {GSIS }}$ & Specification of results according to the GSIS-2017 scale (No.2) \\
\hline 0 & Weakly felt; no damage \\
\hline I & Noticeable, no damage \\
\hline II & Intensification of existing damage \\
\hline III & First new damages of non-structural and architectural elements \\
\hline IV & Slight damage to structural elements \\
\hline V & $\begin{array}{c}\text { Structural damage that may reduce the dynamic resistance of the } \\
\text { building }\end{array}$ \\
\hline VI & $\begin{array}{c}\text { Very large structural damage that could lead to the loss of building } \\
\text { stability }\end{array}$ \\
\hline
\end{tabular}

The GSIS-2017 scale includes the following types of buildings with: traditional and traditional-improved construction, i.e. buildings made of brick or other small-size elements, having wall bearing systems; concrete and/or reinforced concrete bearing structure; frame buildings of reinforced concrete or steel construction.

In addition, the scale includes: effects of vibrations on buildings in poor technical condition and subjected to the influence of continuous deformations characteristic of the III-V category of mining area [15]; effects of vibrations on sensitive historic buildings of historical significance; criteria for empirical assessment of dynamic resilience of buildings subject to seismic effects of mining, developed using the GSIS-2017 scale.

\subsection{Vibration harmfulness assessments based on GSI-GZW ${ }_{\mathrm{KW}}-2012$ and GSIS-2017 scales}

Results of approximate evaluations of considered rockbursts harmfulness using GSI-GZW $\mathrm{KW}_{\mathrm{K}}-2012$ and GSIS-2017 scales, are shown in Figs. 4 and 5 in the cases of velocity and acceleration versions of scales, respectively. All analysed mining shocks are taken into consideration in these figures, and moreover, the mining tremor intensity levels obtained using both the ground and building foundation vibrations measured at the same time, are visible in Figs. 4 and 5. 


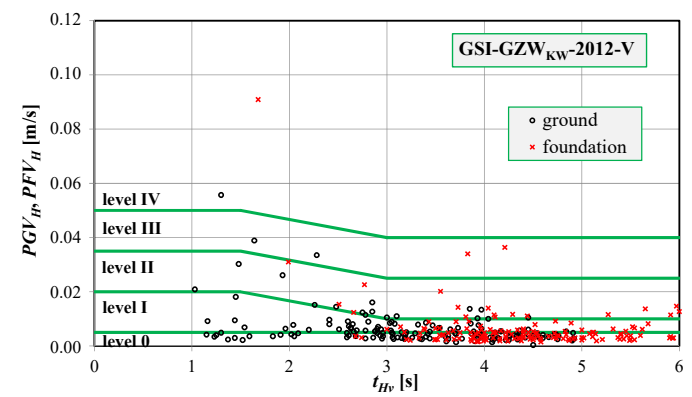

a)

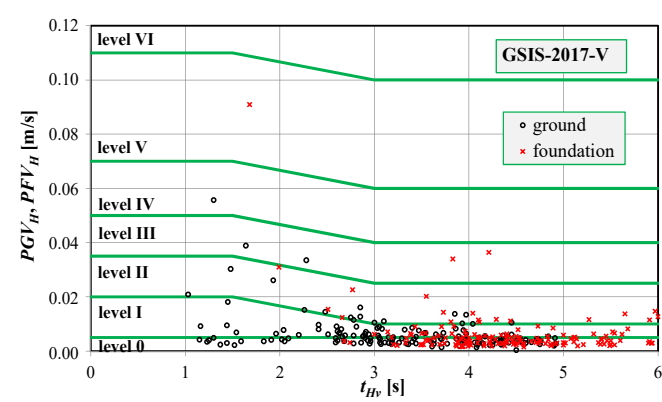

b)

Fig. 4. Assessments of the surface vibrations intensity using velocity version of the scales:

a) GSI-GZW $W_{\mathrm{KW}}-2012-\mathrm{V}$, b) GSIS-2017-V

Some differences in the harmfulness classifications of the rockbursts from the same analysed set, but carried out on the basis of ground vibrations or on the basis of building foundation vibrations simultaneously measured, can be noticed. Table 3 presents summary of rockbursts with the same intensity levels obtained on the basis of free-field $(I G)$ and foundation $(I F)$ vibrations in the case of using the velocity, basic versions of scales, whereas in Fig. 6 the comparisons of the intensity levels of ground and building foundation vibrations in the cases of their inconsistencies are shown. Table 4 and Fig. 7 contain the analogous data, but corresponding to acceleration versions of the Mining Intensity Scales.

It is worth mentioning that because of the same boundaries of the zones corresponding to 0 -III intensity level valid in the case of GSI-GZW $\mathrm{KW}_{-2} 2012$ scale, as well as in the case of GSIS-2017 scale, of course the results obtained for these intensity levels are identical for the both scales. Thus, it is clear that the differences in the vibration intensity assessments obtained using GSI-GZW $\mathrm{KW}_{-}-2012$ or GSIS-2017 scales can occur only in the ranges of the higher intensity levels - IV level in the case of GSI-GZW $\mathrm{KW}-2012$ or IV, V, and VI levels in the case of GSIS-2017 scale. This note applies to both versions of scales: velocity and acceleration.

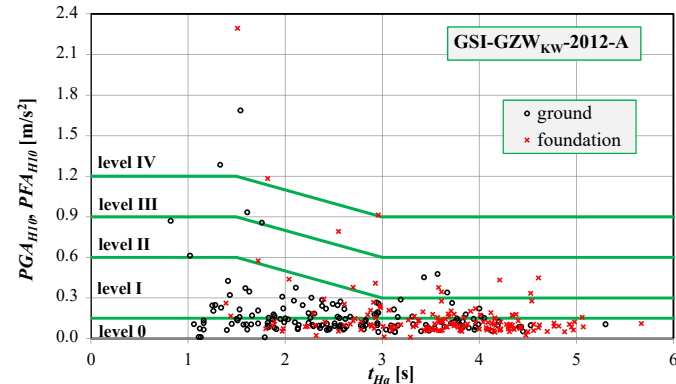

a)

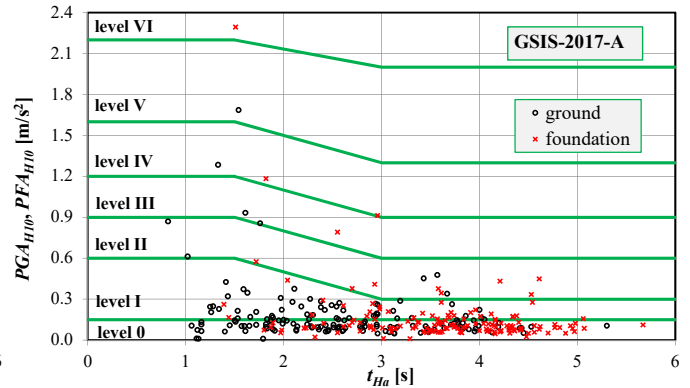

b)

Fig. 5. Assessments of the surface vibrations intensity using acceleration version of the scales:

a) GSI-GZW $\mathrm{KW}_{\mathrm{W}}-2012-\mathrm{A}$, b) GSIS-2017-A

It is visible that for about $80 \%$ of all (156) rockbursts, the same vibration intensity levels were determined on the basis of the simultaneously recorded ground and foundation vibrations, using the velocity versions of both of scales: GSI-GZW $\mathrm{KW}_{-2} 2012-\mathrm{V}$ scale $(80.1 \%)$, as well as GSIS-2017-V (79.5\%). Slightly better and also similar conformity of vibration harmfulness assessments based on the ground and building foundation vibrations was achieved in the cases of acceleration versions of also both of the considered scales: GSI-GZW $\mathrm{KW}_{\mathrm{KW}}-2012-\mathrm{A}$ scale $-84.6 \%$, GSIS-2017-A - 84.0\%. The most of incompatible levels of vibration intensity appeared in the cases of the mine-induced shocks classifying to 0 and I levels of free-field vibration intensity. This applies to the GSI-GZW $\mathrm{KW}_{\mathrm{K}}-2012$, as well as GSIS-2017 scales, in their both versions (velocity 
and acceleration), cf. Figs. 6, 7. However, as it is visible on Figs. 6, 7, different free-field and building foundation vibration harmfulness assessments could appear also in the case of the most intensive rockbursts.

Table 3. Summary of rockbursts with the same intensity levels obtained considering the ground $(I G)$ and foundation $(I F)$ vibrations for scales in velocity version

\begin{tabular}{|c|c|c|c|c|c|c|c|}
\hline \multicolumn{4}{|c|}{ GSI-GZWKW-2012-V } & \multicolumn{4}{|c|}{ GSIS-2017-V } \\
\hline \multirow[b]{2}{*}{$\begin{array}{l}\text { Intensity } \\
\text { level } I G\end{array}$} & \multirow{2}{*}{$\begin{array}{l}\text { Number of } \\
\text { all shocks in } \\
\text { the } I G \\
\text { intensity } \\
\text { level set }\end{array}$} & \multicolumn{2}{|c|}{ Percentage of shocks } & \multirow[b]{2}{*}{$\begin{array}{l}\text { Intensity } \\
\text { level } I G\end{array}$} & \multirow{2}{*}{$\begin{array}{l}\text { Number of } \\
\text { all shocks in } \\
\text { the } I G \\
\text { intensity } \\
\text { level set }\end{array}$} & \multicolumn{2}{|c|}{ Percentage of shocks } \\
\hline & & $\begin{array}{c}\text { All } \\
(156) \\
\text { shocks }\end{array}$ & $\begin{array}{l}\text { Intensity } \\
\text { level set }\end{array}$ & & & $\begin{array}{c}\text { All } \\
(156) \\
\text { shocks }\end{array}$ & $\begin{array}{l}\text { Intensity } \\
\text { level set }\end{array}$ \\
\hline 0 & 75 & $43.6 \%$ & $90.7 \%$ & 0 & 75 & $43.6 \%$ & $90.7 \%$ \\
\hline I & 62 & $25.6 \%$ & $64.5 \%$ & I & 62 & $25.6 \%$ & $64.5 \%$ \\
\hline II & 16 & $9.0 \%$ & $87.5 \%$ & II & 16 & $9.0 \%$ & $87.5 \%$ \\
\hline III & 2 & $1.3 \%$ & $100.0 \%$ & III & 2 & $1.3 \%$ & $100.0 \%$ \\
\hline \multirow{3}{*}{ IV } & \multirow{3}{*}{1} & \multirow{3}{*}{$0.6 \%$} & \multirow{3}{*}{$100.0 \%$} & IV & 1 & $0.0 \%$ & $0.0 \%$ \\
\hline & & & & $\mathrm{V}$ & - & - & - \\
\hline & & & & VI & - & - & - \\
\hline In total & 156 & $80.1 \%$ & - & In total & 156 & $79.5 \%$ & - \\
\hline
\end{tabular}

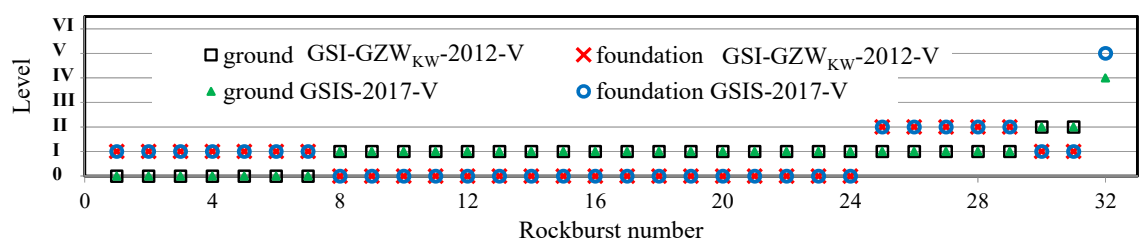

Fig. 6. Levels of the ground and building foundation vibrations intensity in the cases of their inconsistencies - velocity versions of scales

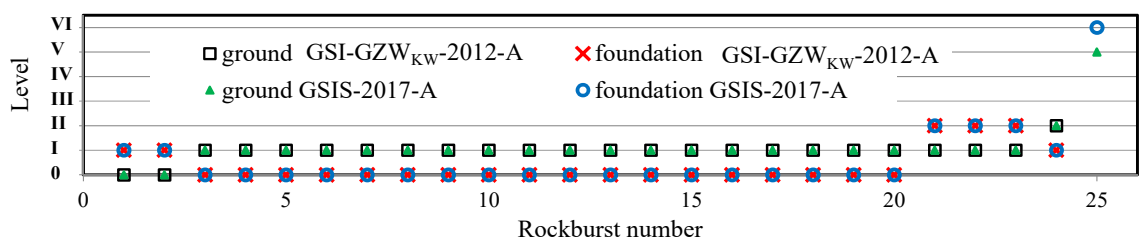

Fig. 7. Levels of the ground and building foundation vibrations intensity in the cases of their inconsistencies - acceleration versions of scales

Table 4. Summary of rockbursts with the same intensity levels obtained considering the ground $(I G)$ and foundation $(I F)$ vibrations for scales in acceleration version

\begin{tabular}{|c|c|c|c|c|c|c|c|}
\hline \multicolumn{4}{|c|}{ GSI-GZW $_{K W}-2012-\mathrm{A}$} & \multicolumn{4}{|c|}{ GSIS-2017-A } \\
\hline \multirow[b]{2}{*}{$\begin{array}{l}\text { Intensity } \\
\text { level } I G\end{array}$} & \multirow{2}{*}{$\begin{array}{l}\text { Number of } \\
\text { all shocks in } \\
\text { the } I G \\
\text { intensity } \\
\text { level set }\end{array}$} & \multicolumn{2}{|c|}{ Percentage of shocks } & \multirow[b]{2}{*}{$\begin{array}{l}\text { Intensity } \\
\text { level } I G\end{array}$} & \multirow{2}{*}{$\begin{array}{l}\text { Number of } \\
\text { all shocks in } \\
\text { the } I G \\
\text { intensity } \\
\text { level set }\end{array}$} & \multicolumn{2}{|c|}{ Percentage of shocks } \\
\hline & & $\begin{array}{c}\text { All } \\
(156) \\
\text { shocks }\end{array}$ & $\begin{array}{l}\text { Intensity } \\
\text { level set }\end{array}$ & & & $\begin{array}{c}\text { All } \\
(156) \\
\text { shocks }\end{array}$ & $\begin{array}{l}\text { Intensity } \\
\text { level set }\end{array}$ \\
\hline 0 & 94 & $58.9 \%$ & $97.9 \%$ & 0 & 94 & $58.9 \%$ & $97.9 \%$ \\
\hline I & 53 & $20.5 \%$ & $60.4 \%$ & I & 53 & $20.5 \%$ & $60.4 \%$ \\
\hline II & 5 & $2.6 \%$ & $80.0 \%$ & II & 5 & $2.6 \%$ & $80.0 \%$ \\
\hline III & 2 & $1.3 \%$ & $100.0 \%$ & III & 2 & $1.3 \%$ & $100.0 \%$ \\
\hline \multirow{3}{*}{ IV } & \multirow{3}{*}{2} & \multirow{3}{*}{$1.3 \%$} & \multirow{3}{*}{$100.0 \%$} & IV & 1 & $0.7 \%$ & $100.0 \%$ \\
\hline & & & & $\mathrm{V}$ & 1 & $0.0 \%$ & $0.0 \%$ \\
\hline & & & & VI & - & - & - \\
\hline In total & 156 & $84.6 \%$ & - & In total & 156 & $84.0 \%$ & - \\
\hline
\end{tabular}


Additionally, apart from the analysis of the impact of the vibration measurement place (free-field or building foundation) on the compatibility of the level of vibration intensity according to the velocity as well as acceleration versions of the considered mining scales, the compatibility of the vibration intensity levels determined on the basis scale in the velocity version, with the assessments obtained using GSI-GZW $\mathrm{KW}_{\mathrm{K}}-2012$ scale in the acceleration version, as well as GSIS-2017 scale, was also investigated, cf. Table 5. It can be concluded that the number of mining tremors with the same intensity levels obtained from velocity and acceleration versions of the both scales (GSI-GZW $\mathrm{KW}-2012$ and GSIS-2017), is similar, despite of the vibration measurement site: $74.3 \%-76.2 \%$ of the all (156) cases of shocks, $c f$. Table 5. It is worth noting that unfortunately, the different assessments of rockburst harmfulness using velocity and acceleration versions of GSIS-2017 concern also the strongest shocks. For instance, using the free-field vibrations, the rockburst with $t_{H v}=1.3 \mathrm{~s}, P G V_{H}=0.056 \mathrm{~m} / \mathrm{s}$ and $t_{H a}=1.54 \mathrm{~s}, P G A_{H 10}=1.69 \mathrm{~m} / \mathrm{s}^{2}$, should be classified to IV intensity level according to GSIS-2017-V, whereas to V intensity level according to GSIS-2017-A. Similarly, based on the foundation vibrations, the mining tremor with $t_{H v}=1.68 \mathrm{~s}, P G V_{H}=0.091 \mathrm{~m} / \mathrm{s}$ and $t_{H a}=1.51 \mathrm{~s}, P G A_{H 10}=2.29 \mathrm{~m} / \mathrm{s}^{2}$, should be classified to V intensity level according to GSIS-2017-V, whereas to VI intensity level according to GSIS-2017-A. But due to the fact that the number of rockbursts with high level of intensity, is very small in the analysed set of cases, these observations could not be simply generalised.

Table 5. Summary of rockbursts with the same intensity levels obtained considering the scales in velocity and acceleration versions

\begin{tabular}{|c|c|c|c|c|}
\hline \multirow{3}{*}{ Intensity $I$} & \multicolumn{4}{|c|}{ Intensity I based on } \\
\cline { 2 - 5 } & \multicolumn{2}{|c|}{ Ground vibrations } & \multicolumn{2}{c|}{ Foundation vibrations } \\
\cline { 2 - 5 } & Percentage of all (156) shocks & Percentage of all (156) shocks \\
\cline { 2 - 5 } & GSI-GZW $\mathrm{KW}-2012$ & GSIS-2017 & GSI-GZW $\mathrm{KW}_{\text {-2012 }}$ & GSIS-2017 \\
\hline 0 & $45.5 \%$ & $45.5 \%$ & $54.5 \%$ & $54.5 \%$ \\
\hline I & $25.0 \%$ & $25.0 \%$ & $16.0 \%$ & $16.0 \%$ \\
\hline II & $3.2 \%$ & $3.2 \%$ & $4.5 \%$ & $4.5 \%$ \\
\hline III & $0.6 \%$ & $0.6 \%$ & $0.6 \%$ & $0.6 \%$ \\
\hline IV & $0.6 \%$ & $0.0 \%$ & $0.6 \%$ & $0.0 \%$ \\
\hline V & - & $0.0 \%$ & - & $0.0 \%$ \\
\hline VI & - & $0.0 \%$ & - & $0.0 \%$ \\
\hline In total & $74.9 \%$ & $74.3 \%$ & $76.2 \%$ & $75.6 \%$ \\
\hline
\end{tabular}

\section{Conclusions}

From the analysis of the results of mine-induced rockburst harmfulness approximate (using Mining Intensity Scales) assessments, the impact of the surface vibration measurement location (ground next to the building or building foundation) on the estimated level of vibrations can be observed in a substantial number of the considered cases of mining shocks. Differences in the classification of the same rockbursts appear taking into account simultaneously measured ground and building foundation vibrations. These conclusions correspond both to the velocity versions, as well as to the acceleration versions of the two applied Mining Intensity Scales.

\section{References}

[1] Poplawski R. F. Seismic parameters and rockburst hazard at mt charlotte mine. Journal of Rock Mechanics and Mining Sciences, Vol. 34, Issue 8, 1997, p. 1213-1228.

[2] Arjang B., Herget G. In situ ground stresses in the Canadian hardrock mines: an update. International Journal of Rock Mechanics and Mining Sciences, Vol. 34, Issues 3-4, 1997, p. 1-16.

[3] Lu C.-P., Dou L.-M., Liu B., Xie Y.-S., Liu H.-S. Microseismic low-frequency precursor effect of bursting failure of coal and rock. Journal of Applied Geophysics, Vol. 79, 2012, p. 55-63.

[4] Holub K. Space-time variations of the frequency-energy relation for mining-induced seismicity in the Ostrava-Karvina mining district. Pure and Applied Geophysics, Vol. 146, Issue 2, 1996, p. 265-280. 
[5] Konicek P., Soucek K., Stas L., Singh R. Long-hole distress blasting for rockburst control during deep underground coal mining. International Journal of Rock Mechanics and Mining Sciences, Vol. 61, 2013, p. 141-153.

[6] Senfaute G., Chambon C., Bigarre P., Guise Y., Josien J. P. Spatial distribution of mining tremors and the relationship to rockburst hazard. Pure and Applied Geophysics, Vol. 150, 1997, p. 451-459.

[7] Srinivasan C., Arora S. K., Benady S. Precursory monitoring of impending rockbursts in Kolar gold mines from microseismic emissions at deeper levels. International Journal of Rock Mechanics and Mining Sciences, Vol. 36, Issue 7, 1999, p. 941-948.

[8] Lovchikov A. V. Review of the strongest rockbursts and mining-induced earthquakes in Russia. Journal of Mining Science, Vol. 49, Issue 4, 2013, p. 572-575.

[9] Steward R. A., Reimold W. U., Charlesworth E. G., Ortlepp W. D. The nature of deformation zone and fault rock related to a recent rockburst at Western Deep Levels Gold Mine, Witwatersrand Basin, South Africa. Tectonophysics, Vol. 337, 2001, p. 173-190.

[10] Mutke G., Dubinski J. Seismic intensity induced by mining in relation to weak earthquakes. Proceedings of 24th World Mining Congress, Rio de Janeiro, Brasil, 2016, p. 419-426.

[11] Baranski A., Kloc L., Kowal T., Mutke G. Mining Vibration Intensity Scale GSI-GZWKW-2012 with respect to the dynamic resistance of buildings. Work Safety and Environmental Protection in Mining, Vol. 6, 2014, p. 3-10, (in Polish).

[12] Baranski A., Chodacki J., Dubinski J., Lurka A., Kowal T., Muszynski L., Mutke G., Stec K. Application rules of Mining Seismic Intensity Scale GSIS-2017 to the prognosis and assessment of the effects of the impact of mine-induced rockbursts on building structures and to the classification of their dynamic resistance. GIG, Katowice, 2017, (in Polish), (Unpublished work).

[13] Dubinski J., Mutke G., Tatara T., Muszynski L., Baranski A., Kowal T. Application rules of the verified Mining Vibration Intensity Scale GSI-GZW $\mathrm{KW}_{\mathrm{W}} 2012$ to the prognosis and assessment of the effects of the impact of rockbursts induced by coal deposits exploitation in the Kompania Weglowa S.A. on building structures and people. Kompania Węglowa, Katowice, 2013, (in Polish), (Unpublished work).

[14] Kuzniar K., Stec K., Tatara T. Approximate classification of mining tremors harmfulness based on free-field and building foundation vibrations. E3S Web of Conferences, Vol. 36, 2018, p. 1-8.

[15] Popiolek E. Protection of Mining Areas. AGH, Krakow, 2009, (in Polish). 